\title{
Squamous Cell Carcinoma Arising In a Benign Cystic Teratoma
}

\author{
Dr. K. Valarmathi, ${ }^{2}$.Dr. Ravi. S, ${ }^{4}$.Dr. A. Jamila. ${ }^{4}$. Dr. G. Selvambigai \\ 1. Associate Professor of Pathology, Chengalpattu Medical College, Chengalpattu, India \\ 2. Professor of Pathology, Chengalpattu Medical College, Chengalpattu, India \\ 3. Associate Professor of Pathology, Chengalpattu Medical College, Chengalpattu, India \\ 4. Associate Professor of Pathology, Chengalpattu Medical College, Chengalpattu, India
}

\begin{abstract}
Mature cystic teratoma is the most common germ cell tumor of ovary comprising 10-20\% of all ovarian tumors (1). Mature cystic teratoma is generally a benign tumor, however cases of malignant transformation occurs in 1-2\% of cases (2). Preoperative diagnosis of malignant transformation is difficult because of the lack of specific symptoms and signs to suggest malignancy. The various types of malignancies which can arise from mature cystic teratoma are Squamous cell carcinoma (70-80\%), adenocarcinoma, melanoma, carcinoid, soft tissue sarcomas, carcinosarcoma and glioblastoma multiforme (3-6). The prognosis of this condition is extremely poor.
\end{abstract}

Key words: Mature cystic teratoma, Squamous cell carcinoma

\section{Introduction:}

A 38 year old female presented with abdominal pain for 7 months. The pain was intermittent, nonradiating and localized to right iliac fossa. CT scan revealed a right adnexal solid and cystic mass. CA-125 levels were normal. The patient underwent a total abdominal hysterectomy with bilateral salpingooophorectomy.

\section{Gross findings:}

\section{Pathological findings:}

Specimen of uterus with cervix measuring 9x7 $55 \mathrm{~cm}, \mathrm{C} / \mathrm{S}-$ Endometrium and Myometrium appears normal. Cervix appears eroded. Right ovary appeared cystic and the cystic mass measured 10x9x8 cm.External surface showed intactcapsule (Fig1). Cut Surface showed uniloculated cyst with a fleshy mural nodule measuring $6 \times 5 \times 3 \mathrm{~cm}$. (Fig 2,3,4). The cyst showed focal projecting hairs and sebaceous putty like material. The left ovary measures $3 \times 3 \times 2 \mathrm{~cm}$, cut section showed small cysts. Both fallopian tubes grossly appeared normal.

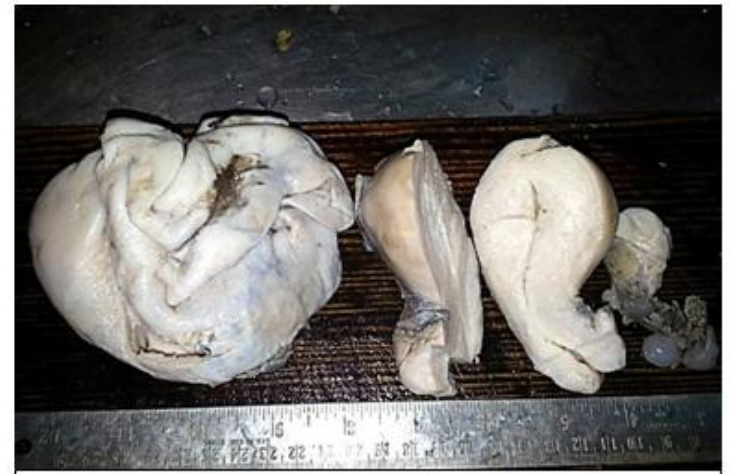

Figure 1: Hysterectomy specimen showing normal appearing uterus with cervix along with the extemal surface of the right ovarian cyst.

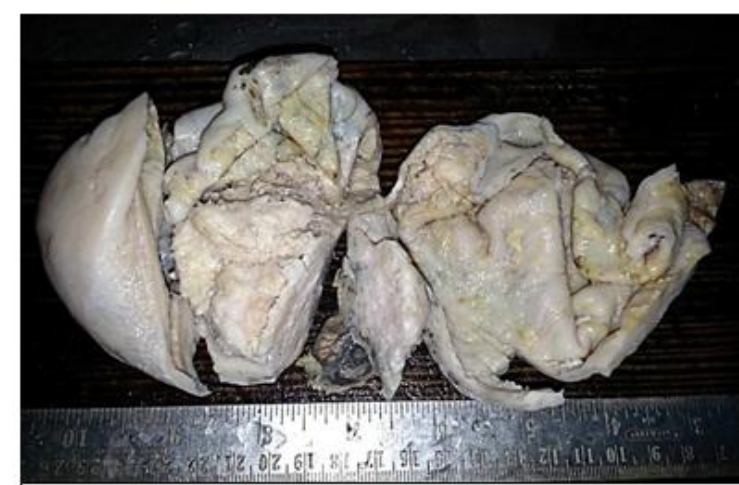

Figure 2: Cut Surface - Uniloculated cyst seen with a fleshy mural nodule measuring $6 \times 5 \times 3 \mathrm{~cm}$. 


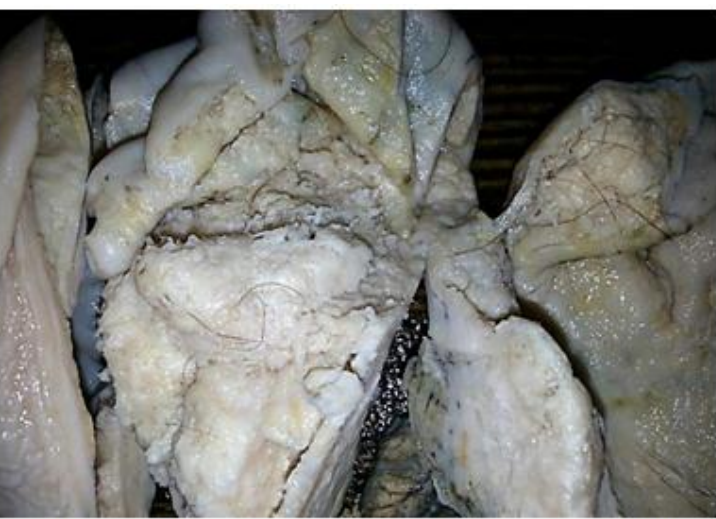

Figure 3: cut surface of the mural nodule - Grey white

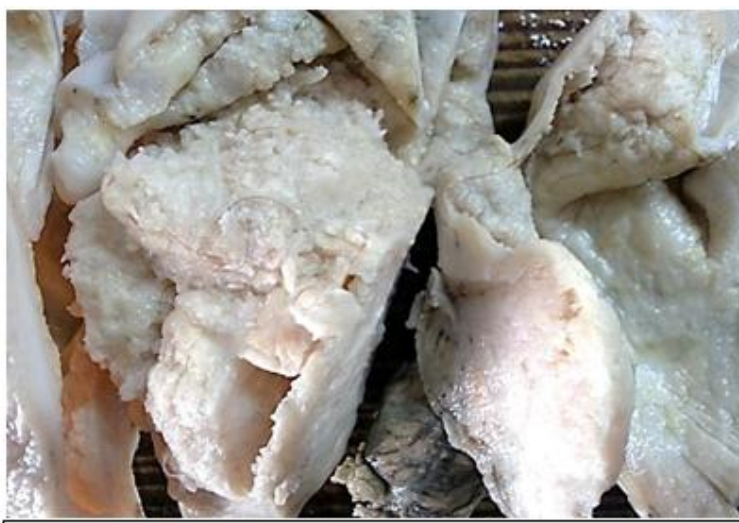

Figure 4: Closer view of the mural nodule along with hair

\section{Microscopic findings:}

Right ovarian cyst showed a lining of mature squamous epithelium with hair follicles. The mural nodule showed moderately differentiated squamous cell carcinoma arising from the squamous epithelium. Areas of necrosis are seen.( Fig 5-10).

Endometrium showed glands in proliferative pattern, Myometrium showed myo-hyperplasia. Cervix shows papillary erosion with chronic cervicitis. Left ovary showed follicular cyst. Both fallopian tubes showed normal histology.

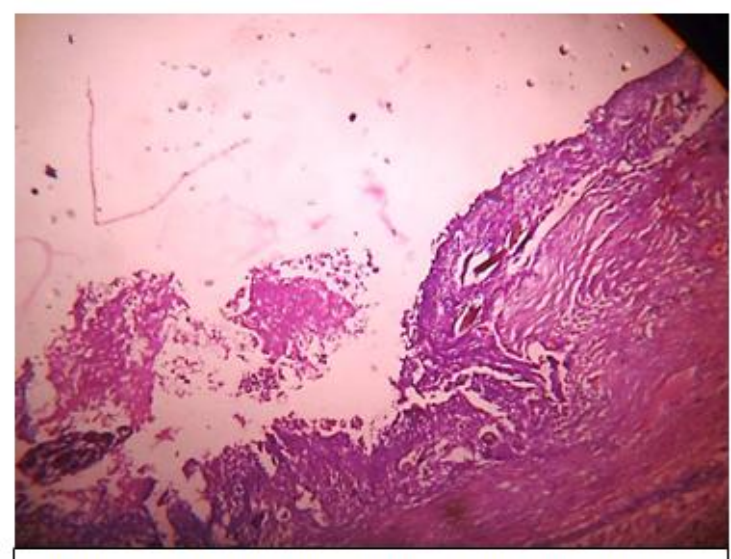

Figure 5: Section shows fibro collagenous cyst wall showing hair follicle $10 \mathrm{X}$

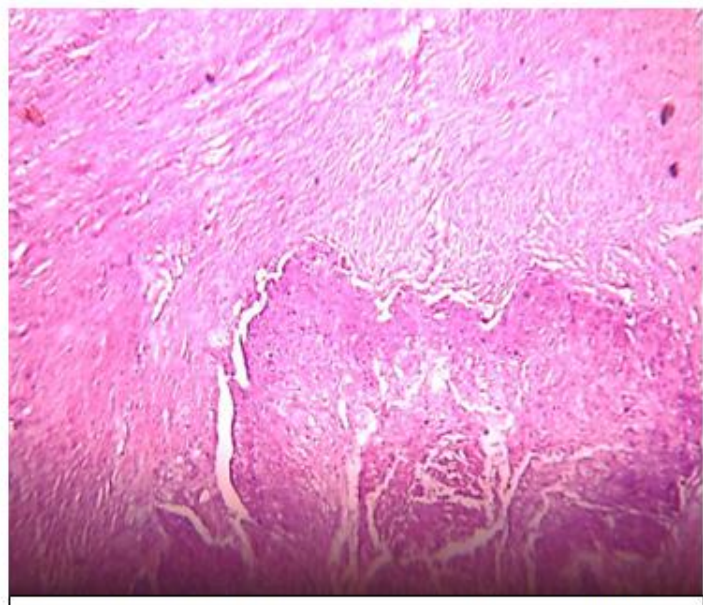

Figure 7: Islands of malignant squamous epithelium $40 \mathrm{X}$

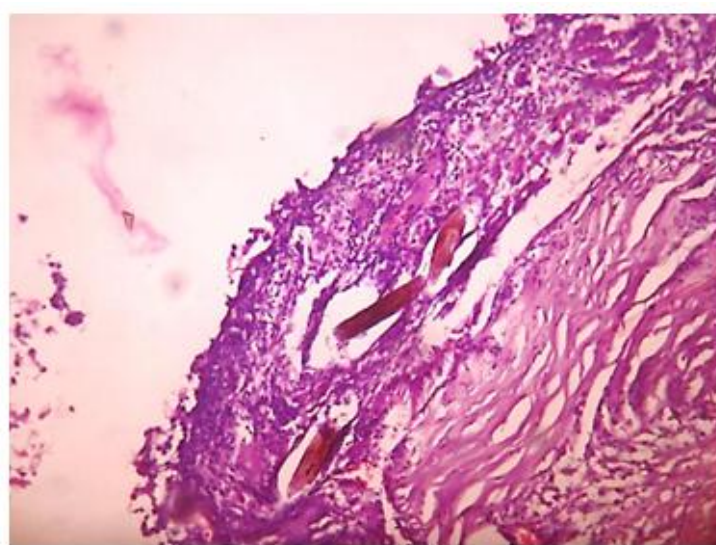

Figure 6: Section shows fibro collagenous cyst wall showing hair follicle $40 \mathrm{X}$

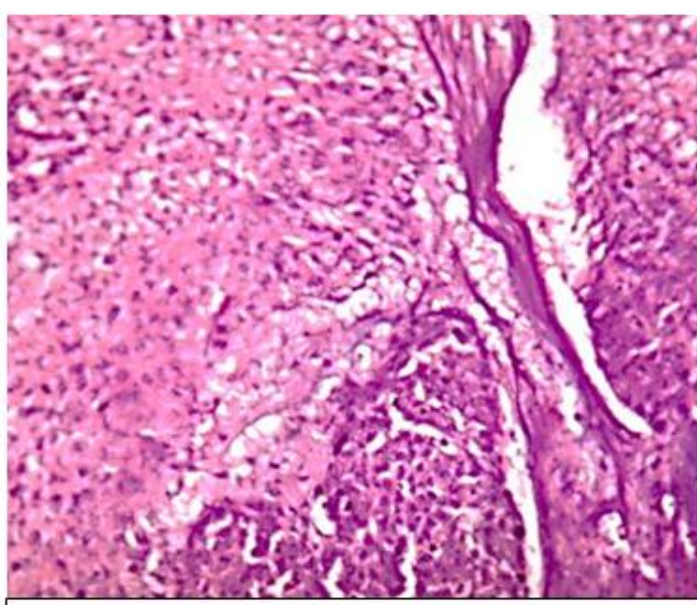

Figure 8: Islands of Malignant Squamous epithelium 

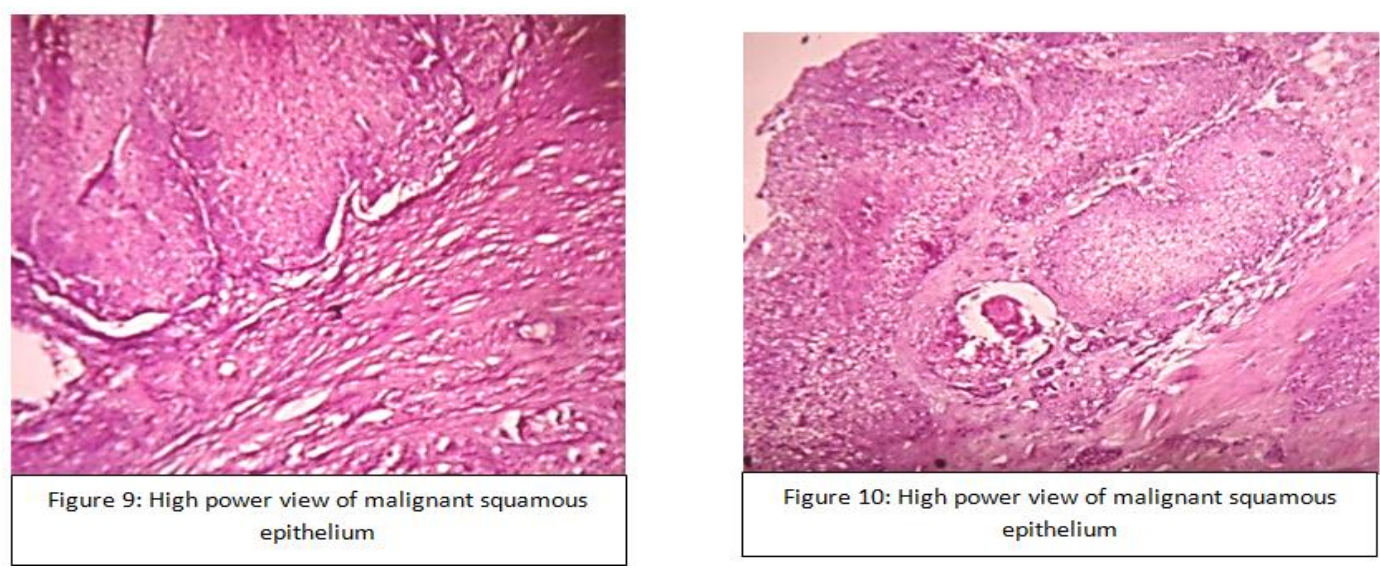

\section{Discussion:}

Malignancies arising from mature cystic teratoma usually present at an older age, but our case has presented at an age of 38. In a mature cystic teratoma, by definition all of the components should appear histologically mature (7). Malignant transformation in the form of a neoplasm with somatic features is an uncommon event. The most common malignant change is squamous cell carcinoma possibly arising from metaplastic columnar epithelium. The malignant transformation is accompanied by complex chromosomal aberrations.

Squamous cell carcinoma arising in mature cystic teratomacan be seen microscopically as nests of squamous cells infiltrating the stroma as well as cyst lined by malignant squamous cells. Other histological patterns are papillary, insular, verruciform as well as spindle cell pattern. In high-grade tumors, squamous differentiation is inconspicuous (8). Microscopically, our case showed nests of malignant squamous cells infiltrating the stroma with keratinisation, mitosis and areas of necrosis. As squamous cell carcinoma arising in mature cystic teratoma is quite rare one, must exclude metastasis particularly from cervix.Stromal invasion by malignant appearing epithelium should be used as definite criteria for categorizing squamous cell carcinoma arising in mature cystic teratomawith malignant transformation

In most instances it is not diagnosed preoperatively. Pre-operative imaging can detect a mature cystic teratoma due to radiologic detection of tissues including teeth, bone \& cartilage. However malignant transformation is very difficult to detect clinically. The risk factors for malignancy in mature cystic teratoma include age and tumor size. Squamous cell carcinoma arises in relatively older patients,particularly after menopause. It is helpful to have regular ovary examination through pelvic USG in middle age for early detection of ovarian lesion. Larger size correlates with increased risk of malignant transformation.

Prognostic indicators include FIGO staging, tumor rupture, vascular invasion and histological type of tumor(9 \&10). Serum tumor markers (SCC-Ag \&CEA) are mandatory for all such lesions.

\section{Conclusion:}

There are no reliable diagnostic tools or prognostic indicators for malignant transformation of mature cystic teratoma. The behavior of these tumors is unpredictable and the role of chemotherapy and radiotherapy remain unclear. The clinicians should keep this rare type of tumor in mind when a dermoid cyst is diagnosed especially in older patients or in larger cysts.

\section{References:}

[1]. Rosai and Ackerman's Surgical Pathology, Eighth edition, Page 1590

[2]. L. Dos Santos, E. Mok, A. Iasonos et al., "Squamous cell carcinoma arising in mature cystic teratoma of the ovary: a case series and review of the literature," Gynecologic Oncology, vol. 105, no. 2, pp. 321-324, 2007.

[3]. A. Hackethal, D. Brueggmann, M. K. Bohlmann, F. E. Franke, H. R. Tinneberg, and K. Münstedt, "Squamous-cell carcinoma in mature cystic teratoma of the ovary: systematic review and analysis of published data," The Lancet Oncology, vol. 9, no. 12, pp. 1173-1180, 2008, Erratum in: The Lancet Oncology, vol. 10, no. 5, p. 446, 2009.

[4]. R. J. Chen, K. Y. Chen, T. C. Chang, B. C. Sheu, S. N. Chow, and S. C. Huang, "Prognosis and treatment of squamous cell carcinoma from a mature cystic teratoma of the ovary," Journal of the Formosan Medical Association, vol. 107, no. 11, pp. 857868,2008

[5]. M. Sakuma, T. Otsuki, K. Yoshinaga et al., "Malignant transformation arising from mature cystic teratoma of the ovary: a retrospective study of 20 cases," International Journal of Gynecological Cancer, vol. 20, no. 5, pp. 766-771, 2010.

[6]. J. Y. Park, D. Y. Kim, J. H. Kim, Y. M. Kim, Y. T. Kim, and J. H. Nam, "Malignant transformation of mature cystic teratoma of the ovary: experience at a single institution," European Journal of Obstetrics Gynecology and Reproductive Biology, vol. 141, no. 2, pp. 173-178, 2008.

[7]. $\quad$ Rosai and Ackerman Surgical pathology - Ninth Edition Page 1688-1689.

[8]. Sternberg SS, Diagnostic Surgical pathology 3rd Edition. Lippincott Williams and Wilkins; 1999. 
[9]. Kikkawa F, Ishikawa H, Tamakoshi K, Nawa A,Suganuma N, Tomoda Y. Squamous cell carcinomaarising from mature cystic teratoma of the ovary:

[10]. A clinico pathologic analysis. Obstet Gynecol. 1997; 89:1017 - 1022.

[11]. Hirakawa T, Tsuneyoshi M, Enjoji M. Squamous cellcarcinoma arising in mature cystic teratoma of the ovary.Clinico pathologic and topographic analysis.Am J SurgPathol.1989; 13: 397 - 405. 